\title{
What Explains Forest Grouse Mortality: Predation Impacts of Raptors, Vole Abundance, or Weather Conditions?
}

\author{
Risto Tornberg, ${ }^{1}$ Vitali Reif, ${ }^{1}$ and Erkki Korpimäki² \\ ${ }^{1}$ Department of Biology, University of Oulu, P.O. Box 3000, 90014 Oulu, Finland \\ ${ }^{2}$ Section of Ecology, Department of Biology, University of Turku, 20014 Turku, Finland
}

Correspondence should be addressed to Risto Tornberg, risto.tornberg@oulu.fi

Received 31 July 2011; Revised 22 December 2011; Accepted 5 January 2012

Academic Editor: Chandra Prakash Kala

Copyright () 2012 Risto Tornberg et al. This is an open access article distributed under the Creative Commons Attribution License, which permits unrestricted use, distribution, and reproduction in any medium, provided the original work is properly cited.

\begin{abstract}
We investigated predation rates of black grouse chicks during 1985-2007 in two localities in western Finland in light of three predation hypothesis: The Alternative Prey Hypothesis (APH) stating that vole-eating generalist predators cause a collapse in grouse reproduction after voles' decline, the Main Prey Hypothesis (MPH), where grouse specialised predators by a lagged response cause an inversely density dependent predation for prey and the Predation Facilitation Hypothesis (PFH), where generalist and specialist predators act in concert. We also studied the effect of weather on grouse reproduction. We found that buzzard predation alone did not support APH, but did so when combined with goshawk predation. Kill rate by goshawks showed a linear response for black grouse chicks but was not density dependent. It, however, explained the losses of chicks but not their autumn density. Combined density of chicks with adults correlated with vole index in the latter study period (since 1994), thus, giving some support for APH. Weather seemed to have no effect on black grouse reproduction. Although buzzards and goshawks took, on average, only $10 \%$ of hatched grouse chicks we conclude that the among-year survival pattern of juvenile forest grouse may largely be determined by raptor predation.
\end{abstract}

\section{Introduction}

Predation mortality has been suggested as one of the forces that drive population cycles of small game animals (forest grouse and hares). Predators can mostly affect population dynamics of grouse in two ways: by lowering reproductive success and by killing adult grouse before breeding season. Whilst adult mortality is spread throughout the year and may be high in spring [1], predation affects reproduction and juvenile survival mainly in summer months. Predators can affect reproduction rate of grouse by direct predation on eggs and chicks or via killing brooding hens. Changes in the reproduction rate may be responsible for year-to-year fluctuations of forest grouse populations [2-6].

The predators hunting on small game can be tentatively divided into two groups: mammal-eaters, which mainly subsist on small mammals (voles, mice, and shrews), and bird-eaters, which prey on small mammals only when vole abundance is high. Impacts of the former group on reproduction of small game have been described by the alternative prey hypothesis (hereafter APH). The APH states that many vole-eating predators increase their densities with increasing densities of voles and then shift to small game (mostly young or eggs) when the abundance of small mammals declines [7]. Thus, the impact of such predators on small game depends on their functional and numerical responses to fluctuations of small mammal populations. Since the latter are the staple food of many predators that also catch small game [7-9], and the amplitude of population fluctuations of small mammals at northern latitudes can be very large [10], such switching may have quite a substantial effect on small game. Ensuing periodical decline of the reproduction success of small game may thus be the cause of population cycles of grouse. Besides observational and correlative studies $[7,8,11,12]$, some experimental support for the APH also exists, for example, in carnivores-grouse system in northern Sweden [13]. Similar mechanism, but connecting fluctuations of snowshoe hares (Lepus americanus) and ruffed grouse (Bonasa umbellus), was discovered in Canada [14].

There are a number of predators that use small game as their main foods, and small mammals are only their alternative prey. If such predators have delayed numerical 
response to the fluctuations of their main prey (grouse), their predation impacts will be heavier in the years when the prey populations are declining or at low numbers (see review [15]). Therefore, in order to distinguish between these two types of predators, we suggest the main prey hypothesis (hereafter $\mathrm{MPH}$ ) stating that grouse-eating predators can reduce grouse populations in the decline and low phase of grouse population cycle. As there are usually both APHtype and MPH-type predators hunting forest grouse in a given area, the actual total impact of predators on grouse populations is defined by the combined impact of these two types of predators (see $[16,17])$. However, only in very few instances the simultaneous pooled impacts of several avian predators have been examined. Results of various studies differed in regards to the impact of raptors on small game. Some older studies have concluded that the impact of raptors on small game is not considerable or is mostly directed on nonterritorial or otherwise inferior or "surplus" birds [18]. However, many recent studies have concluded that the impact of raptors on small game populations can be substantial, at least under certain environmental conditions $[14,15,19-23]$.

Vulnerability of the black grouse hens to goshawk predation has been found to covary with voles so that more hens are depredated during low phase of voles that takes place in peak phase [24-26]. One explanation for this can be so called predation facilitation [27], where predators act in concert. After crash of vole populations, hungry ground predators disturb breeding hens and chase them to talons of raptors that may cause substantial losses in reproduction of grouse. Hence, combined effect of predators using grouse chicks as an alternative prey and those (mainly the goshawk) using grouse as a main prey can also explain mortality pattern of grouse chicks. We call this predation facilitation hypothesis (PFH).

Our previous studies suggest that common buzzards (Buteo buteo) switch from their main prey, Microtus voles, to grouse and their chicks during low vole years and that the predation rate of grouse (pooled functional and numerical responses) by buzzards was higher in the years when vole abundances declined $[11,28]$. Among the birdeating predators, the goshawk (Accipiter gentilis) probably is the most dangerous for adults and chicks of forest grouse $[24,29,30]$. We previously found that the numerical response of goshawks tended to lag behind fluctuations of grouse numbers, suggesting a destabilising impact on grouse populations, particularly during the years when grouse numbers declined [31].

Although impact of birds of prey on small game has been often estimated [15], there are only few attempts to quantify impacts of avian predators on breeding success of grouse (but see [22]). This concerns also tests of the APH, which are mostly qualitative (e.g., $[9,11,32])$. Furthermore, in examining the validity of the MPH in correlative studies, predators are often divided into generalists or specialists, which in reality is rarely the case. Hence, instead of just concentrating only on functional or numerical response of the predator, we should focus on their combination, the total response.
In addition to predation, the crucial influence of weather on breeding success of forest grouse has been suggested long time ago (e.g., [33]). In particular, precipitation and temperature during the first weeks of life or shortly before hatching was found to be important for survival of grouse chicks in Scotland [34] and in Norway [12, 21]. Furthermore, poor weather conditions may increase vulnerability of grouse chicks to predation [21].

In this paper we attempted to estimate the impact of vole- and bird-eating avian predators, the common buzzard (hereafter the buzzard), and the goshawk, on juveniles of black grouse (Tetrao tetrix) in two study areas of western Finland. We studied predation during two summer months (June and July) when the small size of young grouse makes them most vulnerable to predation [35]. We chose the black grouse for study object because it is the most important and numerous prey species of grouse for both raptors $[11,28$, 30]. Our first aim was to test the prediction of the APH that predation impact by mainly vole-eating buzzards on alternative prey, here black grouse chicks, is higher during low years of vole abundance and that buzzard predation impact is reflected in the reproductive success of the black grouse. We suggest that buzzard predation also indicates impacts of other avian predators subsisting on voles as their main foods on black grouse. Secondly, we tested the MPH that predicts that the predator subsisting on birds as its main food, the goshawk in our case, mainly determines losses of chicks and autumn density of black grouse. Thirdly, we analyse the importance of goshawk predation in grouse reproduction and its relationship to vole dynamics (as suggested by the PFH) and weather variables. Finally, we estimated the magnitude of predation pressures by buzzards and goshawks on the black grouse chick mortality.

\section{Material and Methods}

2.1. The Species and the Study Area. We estimated predation impacts of goshawks and buzzards on the black grouse during the nestling period of raptors in June-July (about 60 days) when young raptors stay in nests and the food consumption of raptor families is high, during 1985-2007. The study areas are situated in the South Ostrobothnia region (hereafter SO) in western Finland (ca. 63-64 ${ }^{\circ} \mathrm{N}$, $23-24^{\circ} \mathrm{E}$ ) and in the vicinity of the city of Oulu some $200 \mathrm{~km}$ northwards from SO (ca. $65^{\circ} \mathrm{N}, 25^{\circ} \mathrm{E}$ ). Both areas are characterised by flat terrain with small rivers, creeks, and ditches. Pine- and spruce-dominated forests cover about two thirds of the two study areas, the rest is arable farmland $[11,30]$. Study area covers approximately $3000 \mathrm{~km}^{2}$ in $\mathrm{SO}$ and $1500 \mathrm{~km}^{2}$ in Oulu.

2.2. Raptor Data. The numbers of juvenile and adult grouse killed by raptors were estimated based on the average annual weight proportions of grouse in the diet of raptors (buzzard [30], Goshawk, see Figure 1; the appendix). The proportion of grouse in raptor diets was estimated based on prey remains collected from nests. Since various species of juvenile grouse are difficult to distinguish from one another in prey remains, 


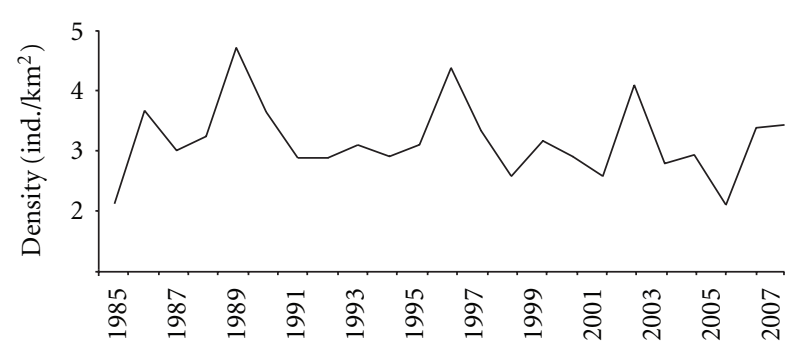

(a)

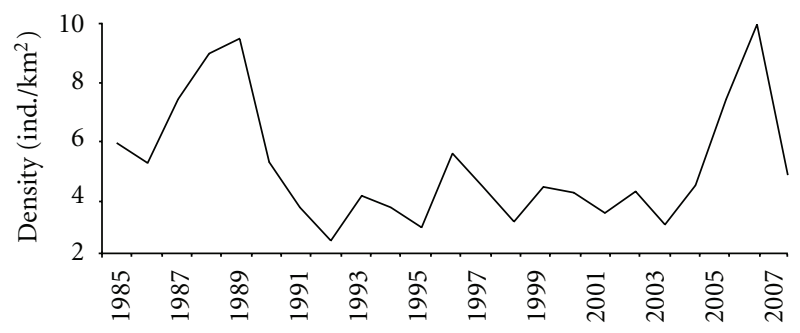

(c)

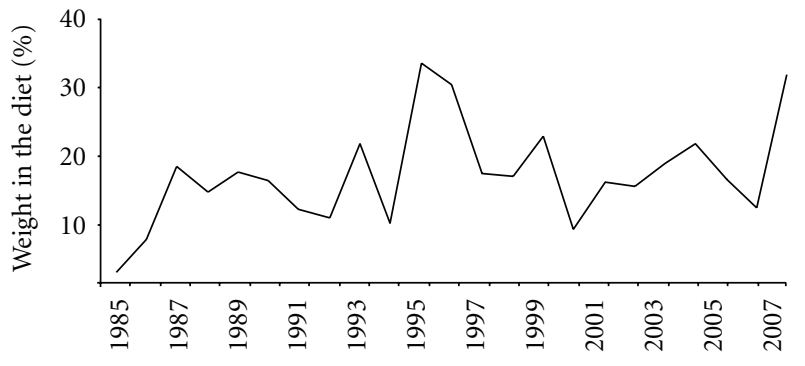

(b)

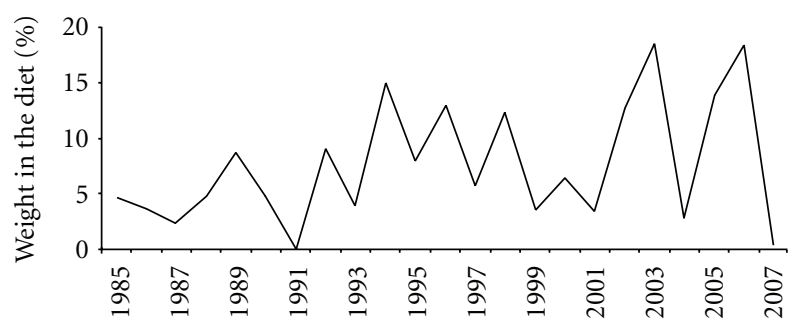

(d)

Figure 1: Density of the black grouse hens in August counts (a), weight proportions, hens in the diet of the goshawk (b), density of black grouse chicks in August counts (c), weight proportions of chicks in the diet of the goshawk (d) in South Ostrobothnia and Oulu regions during 1985-2007.

the proportion of black grouse chicks was approximated as $60 \%$ based on distribution of measured humerus lengths of grouse chicks found in prey remains of buzzards and goshawks $[23,35]$. We used $350 \mathrm{~g}$ as the mean size of juvenile black grouse which is reached approximately in the beginning of the fledging period of both raptors [23]. We further assumed that $75 \%$ of grouse body weight was utilised by raptors [19].

Prey remains of buzzards and goshawks were collected in both study sites from the nests after chicks had fledged (see also [30] for the method). IIn SO collection of prey remains was done in 11-17 buzzard nests annually (14 nests on average) and in 3-12 goshawk nests (7 nests on average) during 1985-1992 [11]. In Oulu study area the collection was done in 4-11 goshawk nests annually ( 8 nests on average) during 1994-2007, respectively.

To define buzzard and goshawk densities in study areas, we applied the mean nearest neighbour distance of territories in that part of the study areas where all territories were likely known (see Newton [36] for methods). For buzzards the mean distance between centres of territories was $2.6 \mathrm{~km}(n=$ $40, \mathrm{SD}=1.3$ ). For goshawks the mean distance between the centres of territories in $\mathrm{SO}$ was $3.1 \mathrm{~km}(n=25, \mathrm{SD}=1.1)$ and $4.0 \mathrm{~km}(n=20, \mathrm{SD}=1.0)$ in Oulu. Assuming that each pair of both raptors hunts up to $3 \mathrm{~km}$ distance from the nest and if all territories were occupied, the theoretical density was 14 pairs $/ 100 \mathrm{~km}^{2}$ for buzzards and 10 and 4.7 pairs $/ 100 \mathrm{~km}^{2}$ for goshawks in SO and Oulu, respectively. By multiplying this density with occupancy rate of each year, we obtained the density estimate of the breeding hawks (see [23]). Nests of both raptors were regularly spaced with $G=0.886$ for buzzard and 0.964 for goshawk. $G$ values near 1 witness for regular spacing pattern (see [37] for method).
The daily food requirements of juvenile raptors were estimated as the mean between the adult and nestling requirements (means for two sexes). The latter was estimated to be $21 \%$ of the body mass for raptor young near the fledgling age when the weight of young is close to adult [38]. The body masses were taken from [39] and our own data (R. Tornberg, unpublished). For adult male and female goshawks the food consumption was taken as 130 and $190 \mathrm{~g} /$ day, respectively [19]. For adult buzzards daily food requirements were calculated based on their body masses linearly related to that of the goshawk, as this method gives acceptable results for species whose body masses do not differ much [40], (the appendix).

2.3. Grouse Data. We used the data on the density of grouse based on annual August counts organised by the Finnish Game and Fisheries Research Institute. These data present the total density of each grouse species and the proportion of juveniles. The method of grouse counts changed from route censuses to wildlife triangles in 1989, when both methods were used [41]. Because the route count gives an estimate of relative abundance of grouse and triangles estimate absolute abundance, we corrected the route data from 1985-1989 with the ratio between the results obtained by these two methods in 1989 ([41], P. Helle, unpublished). The annual length of census routes in SO (during 1985 to 88) varied from 356 to $613 \mathrm{~km}$ and annual number of triangles (since 1989) from 10 to $15(120-180 \mathrm{~km})$ in SO and $15-25(180-300 \mathrm{~km})$ in Oulu.

We calculated a simple estimate for losses of black grouse chicks from hatching till August counts. By multiplying number of adults in August by 4 (a "couple" of black grouse has 8 chicks; [8]), we can with certainty state at least that many eggs were laid in spring. Hence, the number of perished 
TABle 1: Model designs to explain variation in loss of grouse chicks during 2 summer months in study areas of South Ostrobothnia and Oulu in western Finland.

\begin{tabular}{llcc}
\hline Model & & Sign of correlation & Hypothesis \\
\hline 1 & Voles & + & APH \\
2 & Voles, area & + , area effect & APH \\
3 & Voles, area, area*voles &,+ 0 , area effect & APH \\
4 & Goshawk & - & MPH \\
5 & Goshawk, area &,- area effect & MPH \\
6 & Goshawk, voles &,-+ & PFH \\
7 & Goshawk, area, voles, area*voles & PFH \\
8 & Goshawk, voles, weather &,,-+ 0, area effect & PFH, weather \\
9 & Weather &,,-++ & Weather \\
10 & Global model & + & \\
\hline
\end{tabular}

chicks is this number subtracted by the number of chicks observed in August. When calculating the numbers of grouse chicks killed by raptors, we assumed that if a female has been killed during June-July, the whole brood is likely to be lost. Since the hens could have been killed at any time during the two months, and some of them could have already lost part or entire brood by that time, the proportion of hens with broods was assumed to be $50 \%$. This value is an approximate mean between the proportion of successfully incubated females and the proportions of hens with brood in August (P. Helle, unpublished). The average brood size of these hens was evaluated as the mean between the clutch size and the mean brood size in August (P. Helle, unpublished). The total losses of chicks during June-July were calculated as a simple difference between the August and June densities (the appendix).

2.4. Data on Small Mammals and Weather. The abundance of small mammals was estimated biannually (in May and September) at two trapping sites located $15-20 \mathrm{~km}$ south of the study area of SO [10]. In both areas 50-100 Finnish metal snaptraps baited with bread were set at intervals of $10 \mathrm{~m}$ both on forest and field habitats. Trapping lasted 4 days. In Oulu, voles were also snaptrapped biannually at two sites, one of which situating in the study area (10 small quadrates for two days) and another one $30 \mathrm{~km}$ east of it (two lines with 50 traps for two days). The regional synchrony of vole population fluctuations in western Finland has been shown to extend over 70-80 km [42].

The weather data were taken from monthly surveys of the Finnish Meteorology Institute at the Kruunpyy weather observatory in SO study area and at Oulunsalo weather observatory in Oulu study area. We calculated the weather index as the mean temperature divided by the number of rainy days for the main hatching period of grouse chicks from the 10th to the 20th of June, as during this time period newly hatched grouse chicks are most vulnerable to adverse weather [42]. Higher values of the index mean warmer and dryer weather.

2.5. Statistics. We tested density dependence of chick losses and kill rates by $k$-value analysis. For chick losses, $k$ value was defined as log (hatchlings $/ \mathrm{km}^{2} / \mathrm{chicks} / \mathrm{km}^{2}$ in August) and for kill rate as log ratio: $\log$ (hatchlings $/ \mathrm{km}^{2}$ / (hatchlings $/ \mathrm{km}^{2}$-kill rate $\left./ \mathrm{km}^{2}\right)$ ), respectively. These values were related to initial density, that is, log (hatchlings $/ \mathrm{km}^{2}$ ). Density dependence was accepted if regression coefficient calculated between $k$-value and $\log$ (initial density) exceeded $\pm 1[43]$.

To find out whether raptor predation together with other factors may affect the mortality rate of grouse chicks, we performed an analysis of covariance by using generalised linear model procedure with normal distribution and identity link function in statistical package SPSS (16.0). Models were evaluated by Akaike information criteria (AIC) approach [44], which compares the relative fit and parsimony of each candidate model. Lowest AIC value witnesses for the best model taken that difference $(\Delta$-AIC) between successive AIC values are $>2$. In other case models are considered as competing models. Number of chicks of black grouse that died during Jun-July, density of chicks in August counts, and total density of black grouse in August counts as dependent variables, area as a fixed (categorical) factor and number of chicks died from raptor predation (both direct and indirect mortality) and the total index of small mammals (mean for spring and autumn) as covariates. All variables were logtransformed to stabilise residual distributions and detrended to remove trend if observed.

We formed a global model that included all variables and meaningful interaction terms between the fixed factor and covariates of 9 candidate models. Three models tested the APH prediction of correlation between vole index and grouse parameters taking into account the area effect and area-vole interaction, since there is spatial and temporal change in the time series. Interaction term models change in role of vole predators as a mortality factor of grouse due to intensified forestry. Two models tested the MPH, that is, the impact of goshawk predation on grouse parameters. Models that include both goshawk predation and voles tested additive effect of MPH and APH, that is, PFH. The alternative model included area and area-vole interactions. The model where all predictors (goshawk, voles and weather) are included tests additive influence of all main effects. One model tested the effect of weather only (Table 1). 


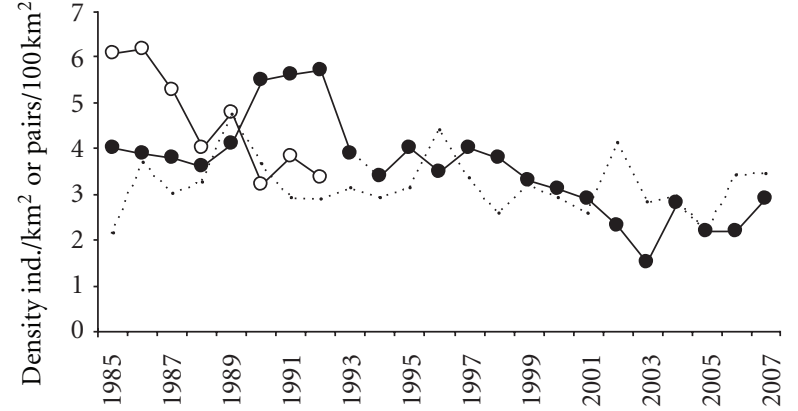

Figure 2: Density of goshawks $(\bullet)$ and buzzards $(\circ)$ in South Ostrobothnia during 1985-1993 and goshawks in Oulu area during 1994-2007. Density of the female black grouse is presented for both study areas (dashed line). Time series of the two study areas are separated by dotted line.

For estimating annual predation impacts, we bootstrapped territory-based weight proportions of grouse chicks, black grouse hens and their densities in the field by 1000 times, and calculated means for them. Predation impact estimates counted from these samples were further sampled by taking 10 estimates and counting means, standard deviations and standard error of means from these to assess confidence intervals for predation impact estimates [44].

\section{Results}

3.1. Black Grouse, Buzzards, and Goshawks. Density of both female and juvenile black grouse fluctuated irregularly and almost synchronously $(r=0.411, P<0.1)$, with peak densities in 1986 (only adults), 1989, 1996, 2001, and 2006 (Figure 1). After a peak year of 1996, the density slightly declined. Mean loss rate of grouse chicks (nest and brood losses) during summer months was $79 \%$. The loss of chicks was related to their density $(B=0.761 \pm 0.106, P<0.001)$ but applying $k$-value analysis, no density dependence was apparent $(B=0.373 \pm 0.888)$. The weight proportion of black grouse hens in the goshawk diet tended to increase in SO but slightly tended to decrease in Oulu, whereas proportions of grouse chicks tended to increase in both areas (Figure 1), but none of the trends were statistically significant.

Buzzard density in SO declined to one half during 1985$92(B=-0.360, P<0.01)$, whereas overall goshawk density slightly increased $(B=0.175$, ns.; Figure 2$)$. Goshawks showed extended peak years during 1990-92 after grouse peak in 1989 whereafter they decreased significantly during 1994-2007 $(B=-0.134, P<0.01)$ approximately at the same rate as grouse. Lagged response pattern for grouse was less pronounced in the latter study period.

3.2. Buzzard and Goshawk Predation on Grouse. The number of grouse chicks killed by buzzards was highest in 1985 when the populations of Microtus voles peaked and crashed during spring 1986 declining till 1988 where after kill rate peaked in 1990 when voles started to increase (Figure 3). Total kill rate of grouse chicks by buzzards did not follow fluctuations of vole abundances, as predicted by the APH (Figure 3; $r=$

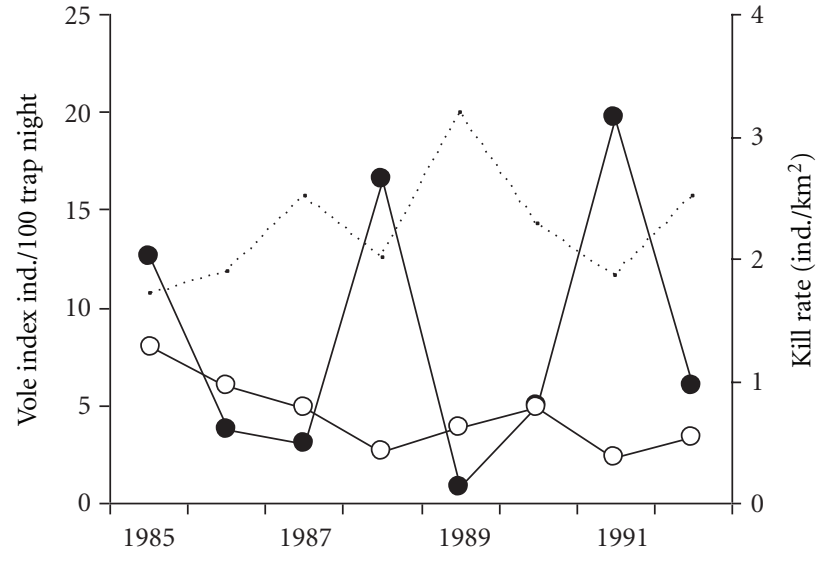

Figure 3: Vole index $(\bullet)$, kill rate of black grouse chicks by buzzards ( $\circ$ ) and combined kill rate by buzzards and goshawks (dashed line) in South Ostrobotnia in western Finland during 1985-1993.

$-0.306, d f=8)$. It did not either explain chick losses $(r=-0.330)$, or chick density of black grouse in August counts $(r=0.154)$. The pooled kill rates of black grouse chicks by buzzards and goshawks correlated negatively and significantly with abundance index of voles $(r=-0.891$, $P<0.01$; Figure 3$)$ but did not with chick losses $(r=0.468)$ or density of chicks in August counts $(r=0.269)$.

Although study area of goshawks changed from SO to Oulu in 1994, connecting the time series may be based since synchrony in the goshawk's breeding performance has been found to be hundreds of kilometers in Finland [45], see Figure 4. We first studied whether goshawk predation was associated with numbers of hatched grouse chicks (i.e., total response). Fitting regression models on the relationship between kill rate and number of hatched chicks, a linear relationship was emergent $\left(R^{2}=0.258, F_{21}=7.303, P<\right.$ $0.05)$, but, based on $k$-value analysis, kill rate showed no real density dependence $(B=0.013 \pm 0.520)$ since slope of the regression line was well below 1. To further explore regulatory ability of the goshawk predation, we bootstrapped time-series values used in our calculations: weight proportion of hens and chicks, density and productivity of goshawks and density of adult hens in autumn counts (whereby we counted number of hatchlings) 1000 times and calculated by this dataset corresponding estimates of chick losses, number of hatchlings and kill rates. $K$-value analysis on this dataset revealed that slope of the regression line was negative $(B=$ -0.074 ) showing that pattern of the goshawk predation on black grouse reproduction is potentially destabilizing.

Univariate analysis gave support for MPH as an explanation for chick losses. The best predictor was the goshawk predation alone (LR $\chi^{2}=6.961, d f=1, P<0.01$ ) (Table 2, Figure 4). Also the next model including goshawk predation and area as predictors was within $\triangle \mathrm{AIC}<2$. Third model including goshawk and voles as predictors was also significant but gave only slight support for PFH since $\triangle \mathrm{AIC}$ was $>2$. APH and weather hypothesis are clearly rather poor predictors of chick losses (Table 2, Figure 6). For example poor weather did not induce high chick losses in 1991 but 
TABLE 2: Generalised linear models explaining variation in chick losses (upper panel) in study areas of South Ostrobotnia and Oulu area in western Finland during 1985-2007. LRT denotes $\log$ ratio $\chi^{2}$ test for model effect.

\begin{tabular}{llcccccc}
\hline Model & & AICc & $\Delta$ AICc & LRT & $d f$ & $P$ & Deviance \\
\hline 4 & Goshawk & 2.129 & 0.000 & 6.961 & 1 & 0.008 & 1.077 \\
5 & Goshawk, area & 3.632 & 1.503 & 8.417 & 2 & 0.015 \\
6 & Goshawk, voles & 4.359 & 2.230 & 7.689 & 2 & 0.021 \\
1 & Voles & 7.431 & 5.302 & 1.658 & 1 & 0.198 & 1.011 \\
8 & Goshawk, voles, weather & 7.665 & 5.536 & 7.690 & 3 & 0.053 \\
9 & Weather & 8.927 & 6.798 & 0.162 & 1 & 0.687 \\
7 & Goshawk, voles, area, area* voles & 9.208 & 7.079 & 9.868 & 4 & 0.043 \\
2 & Voles, area & 9.873 & 7.744 & 2.175 & 2 & 0.337 \\
3 & Voles, area, voles*area & 10.714 & 8.585 & 4.642 & 3 & 0.947 \\
10 & Global model & 17.977 & 15.848 & 10.135 & 6 & 0.200 & 0.119 \\
\hline
\end{tabular}

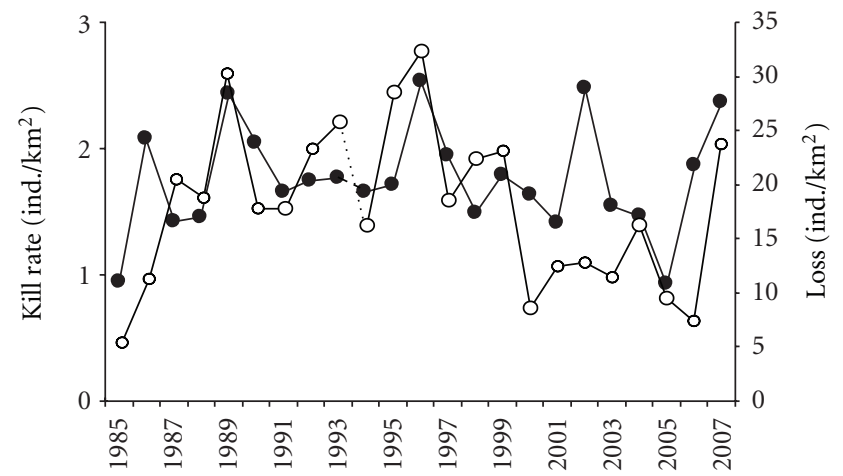

FIGURE 4: Kill rate by goshawks ( $\circ$ ) and losses of black grouse chicks $(\bullet)$ in South Ostrobothnia and Oulu area during 1985-2007. Time series of the two study areas are separated by dotted line.

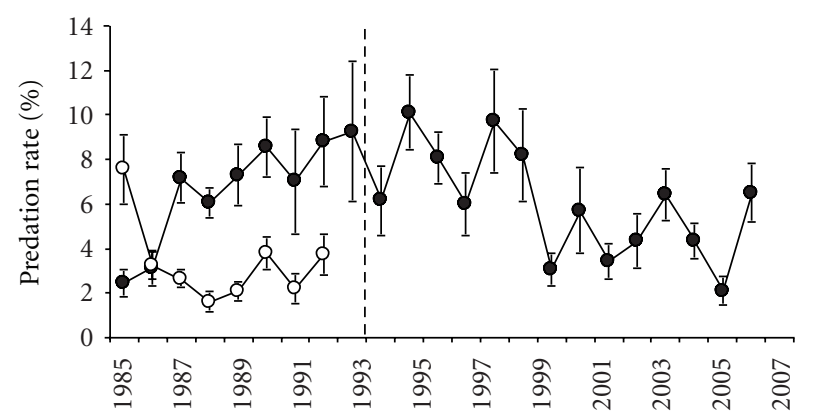

FIgURE 5: Predation rates of black grouse chicks by common buzzards ( $\circ$ ) and goshawks $(\bullet)$ in South Ostrobothnia and Oulu area. Dots denote means and bars 95\% confidence limits for randomised predation rate values. Time series of the two study areas are separated by dotted line.

this was the case in 2006 when weather was exceptionally favorable. Similarly, high losses occur during years of low vole population, like in 1988, 1991 and 2001, but sometimes also during good vole years, like 1996 and 2006. Expectedly, the kill rate by goshawks was significantly positively related to chick losses of black grouse $\left(B=0.269 \pm 0.090, \chi^{2}=8.129\right.$, $P<0.01)$.

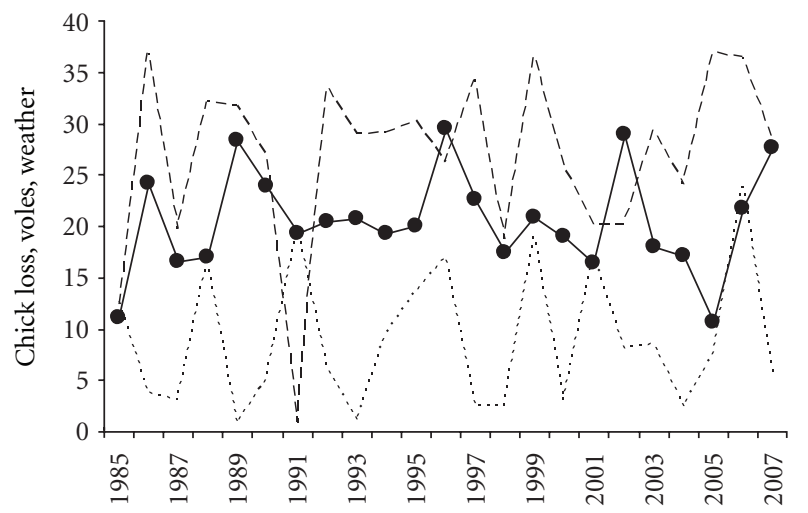

Figure 6: Losses of black grouse chicks $(\bullet)$, vole (dotted line) and weather indices (dashed line) in South Ostrobothnia and Oulu area during 1985-2007.

For other grouse parameters, chick density or total density of black grouse, no models turned out to be significant. Nevertheless, in a model where black grouse density was explained by the voles, area, and area*vole interaction, the latter two were significant as model effects $\left(\chi^{2}=4.467, P<\right.$ 0.05 and $\chi^{2}=4.534, P<0.05$, resp.) but as a whole model was not significant ( $\left.\mathrm{LR} \chi^{2}=4.428\right)$. In SO, the relationship between voles and density of black grouse was negative $(B=$ $-0.218 \pm 0.386)$, but positive in Oulu $(B=0.280 \pm 0.349)$.

3.3. Predation Rate. Predation rate of black grouse chicks by buzzards was the highest (11\%) in 1985 where after it declined roughly to one fourth by 1992 with a mean of $4 \%$ (Figure 5 ). Predation impact of grouse chicks by goshawks varied between 8 and 10\% during 1985-1999 (1986 predation rate was exceptionally low) whereafter it dropped to $3-7 \%$ with the mean of $6.3 \%$. The highest predation rate was in 1995 (10\%). Buzzards appeared to kill $52 \%$ of the black grouse chicks directly whereas goshawks only $17 \%$, the rest being perished with their hens. The maximum pooled predation rates of grouse chicks by two raptors were $12-13 \%$ in 1985,1990 , and 1992 . We tested further how predation impact could explain chick losses. 
A positive relationship was emergent, but it was not significant $(B=0.216 \pm 0.426)$.

\section{Discussion}

Variation of reproductive success in grouse may be crucial in the emergence of cyclic dynamics observed in the forest grouse $[3,4,46]$. Therefore, understanding causes behind it are of utmost importance. Grouse typically suffers from high nest and chick losses [21,47], which was observed also in our data. Chick losses of the black grouse grew with density of the grouse hatchlings, but this process was not density dependent suggesting that reproduction was not directly regulated by any factor, including goshawk predation (see also [22]). It was not surprise that neither total response was density dependent. Although goshawks showed lagged numerical response that should have lead to inverse density dependence found for goshawk-adult grouse [23] and also for other raptor-adult grouse interactions [48, 49], this was, however, not observed for chick predation obviously due to masking effect of functional response. Indeed, total response tracks the proportion of hens more closely than the density of goshawks ( $r=0.518, P=0.011$ and $r=0.390, P=0.066)$. Though our bootstrap test revealed a potential destabilising pattern of predation, lack of density dependence in reality gave no support for MPH in this respect. One reason for lack of density dependence in the pattern of chick predation might arise from the fact that major part of it was due to hen predation. During summer goshawks have many alternative foods to grouse, and female grouse, and their chicks are very secretive. Only when they are very abundant, goshawks can create strong functional response on them (see [29]). During the study years black grouse density was relatively stable and low.

Kill rate by the goshawk explained best the variation in the chick losses of the black grouse, which can be seen as a partial support for MPH though impact of predation was rather low, maximally only $10 \%$. This is relatively low value compared to predation rate found for chicks of Scottish red grouse (Lagopus lagopus scoticus) by hen harriers (Circus cyaneus) who took around 30\% of red grouse hatchlings during similar time period [22]. One explanation could be that our values of predation impact are too conservative. For example, undetectable predation by nonterritorial floaters may lift real predation rate temporarily or continually even many fold depending on the pattern of population dynamics of the bird of prey $[16,50]$. In grouse, almost half of the chicks may die during the first month caused by various factors [21, 22, 46]. Even though this "random" mortality is higher but year-to-year variation possibly lower than the mortality caused by the goshawks, its real impact (elasticity) on the response variable will remain, respectively, also low [5]. It is to remember that our chick loss estimate includes also nest losses that can be substantial [47]. It is likely that goshawk predation dominates chick mortality relatively late in the breeding season suggested by the increased proportion of grouse chicks in the goshawk diet towards late summer [23]. This was also the case for hen harrier predation on red grouse chicks [22] suggesting that raptor predation is an additive mortality factor.

The kill rate of juvenile grouse by buzzards alone appeared to be relatively stable among the years, at least compared to that of goshawks. Therefore, our results indicate that the dietary switching of buzzards from small mammals to grouse may not lead to considerable limiting impacts on grouse populations when not supported by immediate numerical response $[11,28]$. It seems that also other vole predators via prey switching do not have any major effect on grouse parameters suggested by their low covariance with voles. Only during the latter part of the study period (19932007), total density of black grouse was partly explained by vole density indices giving some support for APH. This may due to increased forest fragmentation caused by forestry that is thought to promote nest and brood losses of forest grouse [51]. Small carnivores seem also to modify the survival pattern of adult grouse that may contribute more than reproductive success to their population growth [5]. Although red foxes and other mammalian predators have less grouse in their winter diet than goshawks [52, 53], their numbers outweigh that of goshawks.

Our findings that the pooled kill rates of grouse by buzzards and goshawks were inversely related to vole density lend also some support to the PFH-type pattern of predation, where more female grouse fall prey of goshawks in years of vole scarcity than in those of vole abundance $[25,26,54]$. Effect of this phenomenon was, however, not very apparent in terms of chick losses indicated by our analysis though vole index was negatively related to chick losses.

The weather variables had no obvious association with the grouse losses, autumn density of the black grouse chicks and hens. Therefore, the traditional explanation for poor breeding success in grouse, namely, cool and wet weather during the first weeks of life, was not supported by our analysis. In general, weather variables are poor predictors of grouse fluctuations [55] though weather conditions may modify reproductive success of grouse, at least in utmost cases [12, 21, 34], as it was suspected in 1991. Unfavourable weather conditions can also make grouse chicks more vulnerable to predators [21].

In conclusion, we suggest that the survival pattern of juvenile forest grouse may be determined by the predation impacts of birds of prey, in particular, of goshawks. Since proportion of chicks taken by the goshawks was stable, this predation seems to have only a limiting effect on grouse reproduction. In a broad view goshawk predation on grouse chicks may also incorporate a destabilising element on the grouse reproduction. Because the numbers of chicks depend strongly on the numbers of grouse hens in spring, necessarily none of the factors studied solely or together explains their autumn density. The role of mammalian predation in determining the autumn density has probably increased during the last decades as a consequence of heavy forestry impact on the landscape.

\section{Appendix}

For more details see Table 3. 
TABLE 3: Some of the main original data used and calculation performed for estimation of raptor predation impact on juvenile grouse (only mean values are presented).

\begin{tabular}{|c|c|c|c|c|c|}
\hline \multirow{2}{*}{$\begin{array}{l}\text { Weight of black grouse hen, } \mathrm{g}\left(W_{\mathrm{h}}\right) \\
\text { Weight of black grouse chick, } \mathrm{g}\left(W_{\mathrm{c}}\right)\end{array}$} & \multicolumn{2}{|c|}{ Both raptors } & \multicolumn{3}{|c|}{950} \\
\hline & \multicolumn{2}{|c|}{ Both raptors } & \multicolumn{3}{|c|}{350} \\
\hline \multirow{4}{*}{ Weight proportion of the black grouse hens and chicks, $\%\left(\mathrm{WP}_{\mathrm{hc}}\right)$} & \multirow{2}{*}{ Goshawk } & Hens & & 17.3 & \\
\hline & & Chicks & & 7.6 & \\
\hline & \multirow{2}{*}{ Buzzard } & Hens & & 8.0 & \\
\hline & & Chicks & & 11.8 & \\
\hline Grouse body weight utilised by raptors, $\%(U)$ & \multicolumn{2}{|c|}{ Both raptors } & & 75 & \\
\hline \multirow{3}{*}{ Daily food requirements of male $(m)$, female $(f)$ and juvenile $(j)$ raborts, g/day $\left(\operatorname{DFR}_{m f j}\right)$} & \multirow{2}{*}{\multicolumn{2}{|c|}{ Goshawk }} & Male & Fem. & Juv. \\
\hline & & & 130 & 190 & 196 \\
\hline & \multicolumn{2}{|c|}{ Buzzard } & 100 & 126 & 138 \\
\hline \multirow[t]{2}{*}{ Ratio of the black grouse among grouse chicks in the diet of raptors, \% $(P)$} & \multicolumn{2}{|c|}{ Goshawk } & & 60 & \\
\hline & \multicolumn{2}{|c|}{ Buzzard } & & 60 & \\
\hline \multirow[t]{2}{*}{ Length of the study period $(L)$} & \multicolumn{2}{|c|}{ Goshawk } & & 60 & \\
\hline & \multicolumn{2}{|c|}{ Buzzard } & & 60 & \\
\hline \multirow{3}{*}{ Maximum density of raptor population nests $/ 100 \mathrm{~km}^{2}(D)$} & \multirow{2}{*}{ Goshawk } & SO & & 10 & \\
\hline & & Oulu & & 4.7 & \\
\hline & Buzzard & SO & & 14 & \\
\hline Occupancy rate of the territory (Or) & \multicolumn{2}{|c|}{ Goshawk, buzzard } & \multicolumn{3}{|c|}{56,33} \\
\hline Productivity chicks/occ. terr. (Prod) & \multicolumn{2}{|c|}{ Goshawk, buzzard } & \multicolumn{3}{|c|}{$2.1,1.2$} \\
\hline Clutch size (Cs) & \multicolumn{2}{|c|}{ Black grouse } & \multicolumn{3}{|c|}{8} \\
\hline Brood size (Bs) & \multicolumn{2}{|c|}{ Black grouse } & \multicolumn{3}{|c|}{6} \\
\hline Density of hens in August $\left(D_{\mathrm{h}}\right)$ & \multicolumn{2}{|c|}{ Black grouse } & \multicolumn{3}{|c|}{3.2} \\
\hline Density of chicks in August $\left(D_{c}\right)$ & \multicolumn{2}{|c|}{ Black grouse } & \multicolumn{3}{|c|}{10.5} \\
\hline Density of hatchlings $D_{\text {hatch }}=\left(D_{\mathrm{h}} \mathrm{Cs}\right)$ & Black & ouse & & 25.4 & \\
\hline Loss of chicks $\left(D_{\text {hatch }}-D_{c}\right)$ & Black & ouse & & 20.5 & \\
\hline Consumption of a hawk family & $C=1$ & $\mathrm{FR}_{m}+\mathrm{D}$ & $f+\operatorname{Prc}$ & $\mathrm{d} \times \mathrm{DFR}_{j}$ & \\
\hline Kill rate of adult hens & & $\mathrm{h}_{\mathrm{h}}=(C \times$ & $J \times W P$ & $\mathrm{~h}) / W_{\mathrm{h}}$ & \\
\hline Kill rate of chicks & & $=(C \times L$ & $\times P \times h$ & $\left(P_{\mathrm{c}}\right) / W_{\mathrm{c}}$ & \\
\hline Total kill rate of black grouse chicks & $\mathrm{TKR}_{\mathrm{c}}$ & $\mathrm{OrD} \times$ & $5 \mathrm{KR}_{\mathrm{h}} \mathrm{B}$ & $\left.+\mathrm{KR}_{\mathrm{c}}\right) \times 1$ & \\
\hline
\end{tabular}

\section{Acknowledgments}

The authors would like to thank Sven Jungell, Kauko Huhtala, Pekka Helle, Pentti Valkeajärvi, Gilbert Ludwig, and the Ringing Centre of the Finnish Museum of Natural History, Helsinki University for providing various unpublished data, Esa Hohtola and Jari Oksanen for advice in the data analysis, and Jari Valkama and Steve Redpath for comments on the manuscript. This study was partly funded by the Environmental Graduate School of EnviroNet and the Faculty of Science of the University of Oulu (to VR).

\section{References}

[1] T. Willebrand, "Demography and ecology of a black grouse (Tetrao tetrix L) population," Acta Universitatis Upsaliensis, vol. 148, pp. 1-44, 1988.

[2] K. Kauhala and P. Helle, "The impact of predator abundance on grouse populations in Finland-a study based on wildlife monitoring counts," Ornis Fennica, vol. 79, no. 1, pp. 14-25, 2002.

[3] H. Lindén, "Characteristics of tetraonid cycles in Finland," Finnish Game Research, vol. 46, pp. 34-42, 1989.
[4] J. Lindström, E. Ranta, M. Lindén, and H. Lindén, "Reproductive output, population structure and cyclic dynamics in Capercaillie, Black Grouse and Hazel Grouse," Journal of Avian Biology, vol. 28, no. 1, pp. 1-8, 1997.

[5] H. Steen and K. E. Erikstad, "Sensitivity of willow grouse Lagopus lagopus population dynamics to variations in demographic parameters," Wildlife Biology, vol. 2, no. 1, pp. 27-35, 1996.

[6] T. Willebrand, "Breeding and age in female black grouse Tetrao tetrix," Ornis Scandinavica, vol. 23, no. 1, pp. 29-32, 1992.

[7] P. Angelstam, E. Lindström, and P. Widén, "Role of predation in short-term population fluctuations of some birds and mammals in Fennoscandia," Oecologia, vol. 62, no. 2, pp. 199208, 1984.

[8] G. L. Dell'Arte, T. Laaksonen, K. Norrdahl, and E. Korpimäki, "Variation in the diet composition of a generalist predator, the red fox, in relation to season and density of main prey," Acta Oecologica, vol. 31, no. 3, pp. 276-281, 2007.

[9] E. Korpimäki and K. Norrdahl, "Can the alternative prey hypothesis explain the occurrence of short-term population cycles of small game in Finland?" Suomen Riista, vol. 43, pp. 72-84, 1997.

[10] E. Korpimäki, K. Norrdahl, O. Huitu, and T. Klemola, "Predator-induced synchrony in population oscillations of 
coexisting small mammal species," Proceedings of the Royal Society B, vol. 272, no. 1559, pp. 193-202, 2005.

[11] V. Reif, R. Tornberg, S. Jungell, and E. Korpimäki, "Diet variation of common buzzards in Finland supports the alternative prey hypothesis," Ecography, vol. 24, no. 3, pp. 267274,2001

[12] J. B. Steen, H. Steen, N. C. Stenseth, S. Myrberget, and V. Marcstrom, "Microtine density and weather as predictors of chick production in willow ptarmigan, Lagopus 1. lagopus," Oikos, vol. 51, no. 3, pp. 367-373, 1988.

[13] V. Marcstrom, R. E. Kenward, and E. Engren, "The impact of predation on boreal tetraonids during vole cycles: an experimental study," Journal of Animal Ecology, vol. 57, no. 3, pp. 859-872, 1988.

[14] L. B. Keith and D. H. Rusch, "Predation's role in the cyclic fluctuations of ruffed grouse," in Proceedings of the 19th International Ornithological Congress, pp. 699-732, 1989.

[15] J. Valkama, E. Korpimäki, B. Arroyo et al., "Birds of prey as limiting factors of gamebird populations in Europe: a review," Biological Reviews of the Cambridge Philosophical Society, vol. 80, no. 2, pp. 171-203, 2005.

[16] C. Rohner, F. I. Doyle, and J. N. M. Smith, "Great horned owls," in Ecosystem Dynamics of the Boreal Forest: The Kluane Project, C. J. Krebs et al., Ed., pp. 339-375, Oxford University Press, Oxford, UK, 2001.

[17] L. B. Keith, A. W. Todd, C. J. Brand, R. S. Adamcik, and D. H. Rusch, "An analysis of predation during a cycle fluctuation of snowshoe hares," International Congress of Game Biology, vol. 13, pp. 151-175, 1977.

[18] P. L. Errington, "Predation and vertebrate populations," Quarterly Review of Biology, vol. 21, pp. 144-177, 1946.

[19] R. E. Kenward, V. Marcström, and M. Karlbom, "Goshawk winter ecology in Swedish pheasant habitats," Journal of Wildlife Management, vol. 45, pp. 397-408, 1981.

[20] H. Linden and M. Wikman, "Goshawk predation on tetraonids: availability of prey and diet of the predator in the breeding season," Journal of Animal Ecology, vol. 52, no. 3, pp. 953-968, 1983.

[21] P. Wegge and L. Kastdalen, "Pattern and causes of natural mortality of capercaille, Tetrao urogallus, chicks in a fragmented boreal forest," Annales Zoologici Fennici, vol. 44, no. 2, pp. 141$151,2007$.

[22] S. J. Thirgood, S. M. Redpath, P. Rothery, and N. J. Aebischer, "Raptor predation and population limitation in red grouse," Journal of Animal Ecology, vol. 69, no. 3, pp. 504-516, 2000.

[23] R. Tornberg, "Pattern of goshawk Accipiter gentilis predation on four forest grouse species in northern Finland," Wildlife Biology, vol. 7, no. 4, pp. 245-256, 2001.

[24] P. Widen, "Goshawk predation during winter, spring and summer in a boreal forest area of central Sweden," Holarctic Ecology, vol. 10, no. 2, pp. 104-109, 1987.

[25] V. Selås, "Vulnerability of Black Grouse (Tetrao tetrix) hens to Goshawk (Accipiter gentilis) predation in relation to vole cycles," Journal fur Ornithologie, vol. 144, no. 2, pp. 186-196, 2003.

[26] R. Tornberg, P. Helle, and E. Korpimäki, "Vulnerability of black grouse hens to goshawk predation: result of food supply or predation facilitation?" Oecologia, vol. 166, no. 3, pp. 577584,2010

[27] E. Korpimäki, V. Koivunen, and H. Hakkarainen, "Microhabitat use and behavior of voles under weasel and raptor predation risk: predator facilitation?" Behavioral Ecology, vol. 7, no. 1, pp. 30-34, 1996.
[28] V. Reif, S. Jungell, E. Korpimäki, R. Tornberg, and S. Mykrä, "Numerical response of common buzzards and predation rate of main and alternative prey under fluctuating food conditions," Annales Zoologici Fennici, vol. 41, no. 4, pp. 599607,2004

[29] S. Sulkava, "Zur Nahrungsbiologie des Habichts, Accipiter gentilis (L)," Aquilo Ser Zoologica, vol. 3, pp. 1-103, 1964.

[30] R. Tornberg, "Prey selection of the Goshawk Accipiter gentilis during the breeding season: the role of prey profitability and vulnerability," Ornis Fennica, vol. 74, no. 1, pp. 15-28, 1997.

[31] R. Tornberg, E. Korpimäki, S. Jungell, and V. Reif, "Delayed numerical response of goshawks to population fluctuations of forest grouse," Oikos, vol. 111, no. 2, pp. 408-415, 2005.

[32] P. Angelstam, E. Lindstrom, and P. Widen, "Synchronous short-term population fluctuations of some birds and mammals in Fennoscandia-occurrence and distribution," Holarctic Ecology, vol. 8, no. 4, pp. 285-298, 1985.

[33] L. Siivonen, "The problem of the short-term fluctuations in numbers of tetraonids in Europe," Papers Game Research, vol. 19, pp. 1-44, 1957.

[34] R. Moss, "Rain, breeding success and distribution of capercaillie Tetrao urogallus and black grouse Tetrao tetrix in Scotland," Ibis, vol. 128, no. 1, pp. 65-72, 1986.

[35] V. Reif, R. Tornberg, and K. Huhtala, "Juvenile grouse in the diet of some raptors," Journal of Raptor Research, vol. 38, no. 3, pp. 243-249, 2004.

[36] I. Newton, The Sparrowhawk, Poyser.

[37] D. Brown and P. Rothery, "Randomness and local regularity of points in a plane," Biometrika, vol. 65, no. 1, pp. 115-122, 1978.

[38] K. Newgrain, P. Olsen, B. Green, N. Mooney, N. Brothers, and R. Bartos, "Food consumption rates of free-living raptor nestlings," in Australian Raptor Studies, pp. 274-284, Australasian Raptor Association, Royal Australasian Ornithologists Union, 1993.

[39] S. Cramp and K. E. L. Simmon, Eds., The Birds of the Western Palearctic, vol. 2, Oxford University Press, Oxford, UK, 1980.

[40] R. H. Peters, The Ecological Implications of Body Size, Cambridge University Press, Cambridge, UK, 1986.

[41] H. Lindén, E. Helle, P. Helle, and M. Wikman, "Wildlife triangle scheme in Finland: methods and aims for monitoring wildlife populations," Finnish Game Research, vol. 49, pp. 411, 1996.

[42] T. Slagsvold and T. Grasaas, "Autumn population size of the capercaillie in relation to weather," Ornis Scandinavica, vol. 10, pp. 37-41, 1979.

[43] M. Begon, J. L. Harper, and C. R. Townsend, Individuals Populations and Communities, Blackwell, Boston, Mass, USA, 1990.

[44] K. B. Burnham and D. R. Anderson, Model Selection and Multimodel Inference, Springer, New York, NY, USA, 2002.

[45] E. Ranta, P. Byholm, V. Kaitala, P. Saurola, and H. Lindén, "Spatial dynamics in breeding performance of a predator: the connection to prey availability," Oikos, vol. 102, no. 2, pp. 391396, 2003.

[46] R. Moss and A. Watson, "Population cycles in birds of the grouse family (Tetraonidae)," Advances in Ecological Research, vol. 32, pp. 53-111, 2001.

[47] P. Wegge and T. Storaas, "Nest loss in capercaillie and black grouse in relation to the small rodent cycle in southeast Norway," Oecologia, vol. 82, no. 4, pp. 527-530, 1990.

[48] Ó. K. Nielsen, "Gyrfalcon predation on ptarmigan: numerical and functional responses," Journal of Animal Ecology, vol. 68, no. 5, pp. 1034-1050, 1999. 
[49] S. M. Redpath and S. J. Thirgood, "Numerical and functional responses in generalist predators: hen harriers and peregrines on Scottish grouse moors," Journal of Animal Ecology, vol. 68, no. 5, pp. 879-892, 1999.

[50] R. E. Kenward, S. S. Walls, K. H. Hodder, M. Pahkala, S. N. Freeman, and V. R. Simpson, "The prevalence of non-breeders in raptor populations: evidence from rings, radio-tags and transect surveys," Oikos, vol. 91, no. 2, pp. 271-279, 2000.

[51] S. Kurki, A. Nikula, P. Helle, and H. Lindén, "Landscape fragmentation and forest composition effects on grouse breeding success in boreal forests," Ecology, vol. 81, no. 7, pp. 1985-1997, 2000.

[52] O. Huitu, K. Norrdahl, and E. Korpimäki, "Landscape effects on temporal and spatial properties of vole population fluctuations," Oecologia, vol. 135, no. 2, pp. 209-220, 2003.

[53] R. Tornberg and A. Colpaert, "Survival, ranging, habitat choice and diet of the Northern Goshawk Accipiter gentilis during winter in northern Finland," Ibis, vol. 143, no. 1, pp. 41-50, 2001.

[54] P. Widen, H. Andren, P. Angelstam, and E. Lindstrom, "The effect of prey vulnerability: goshawk predation and population fluctuations of small game," Oikos, vol. 49, no. 2, pp. 233-235, 1987.

[55] J. Lindstrom, "Weather and grouse population dynamics," Wildlife Biology, vol. 2, no. 2, pp. 93-99, 1996. 

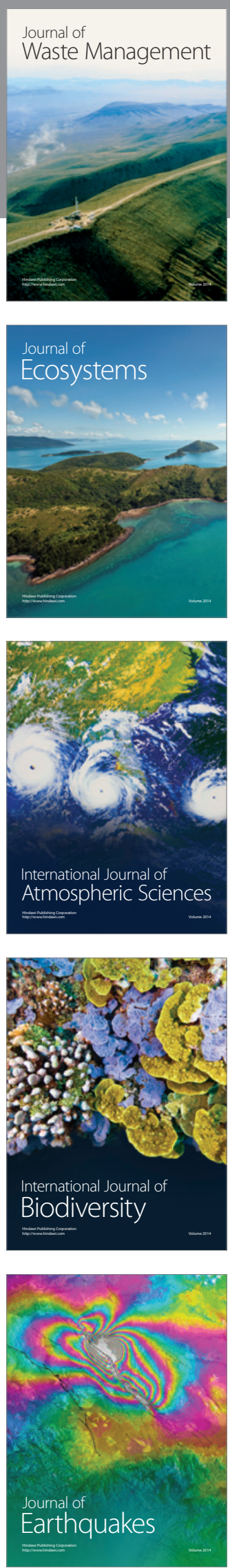
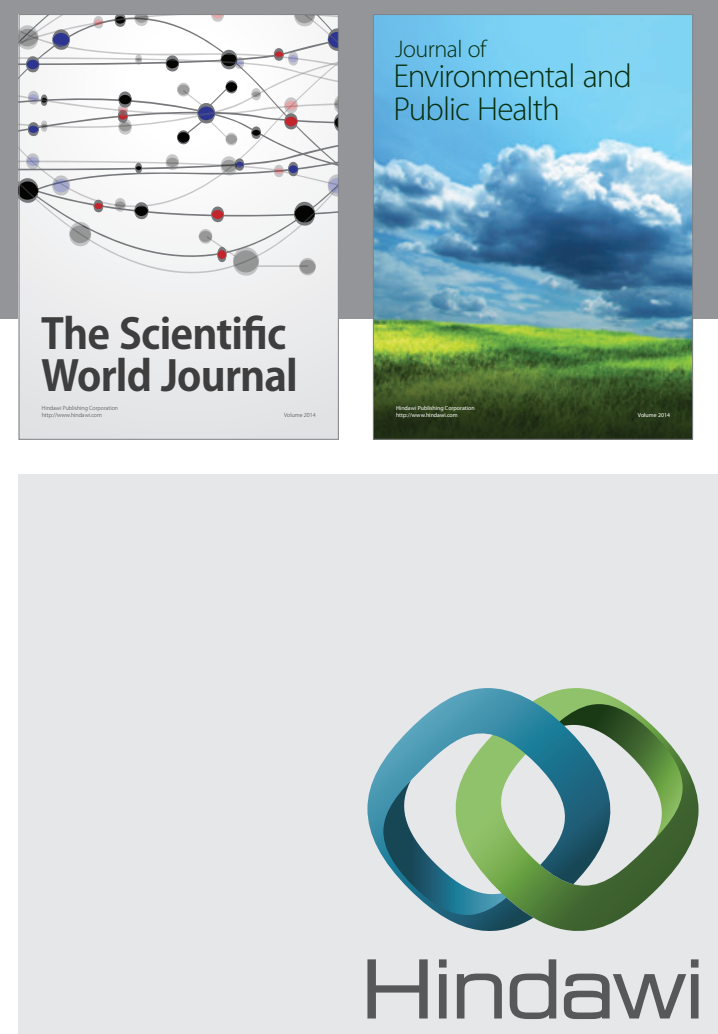

Submit your manuscripts at

http://www.hindawi.com
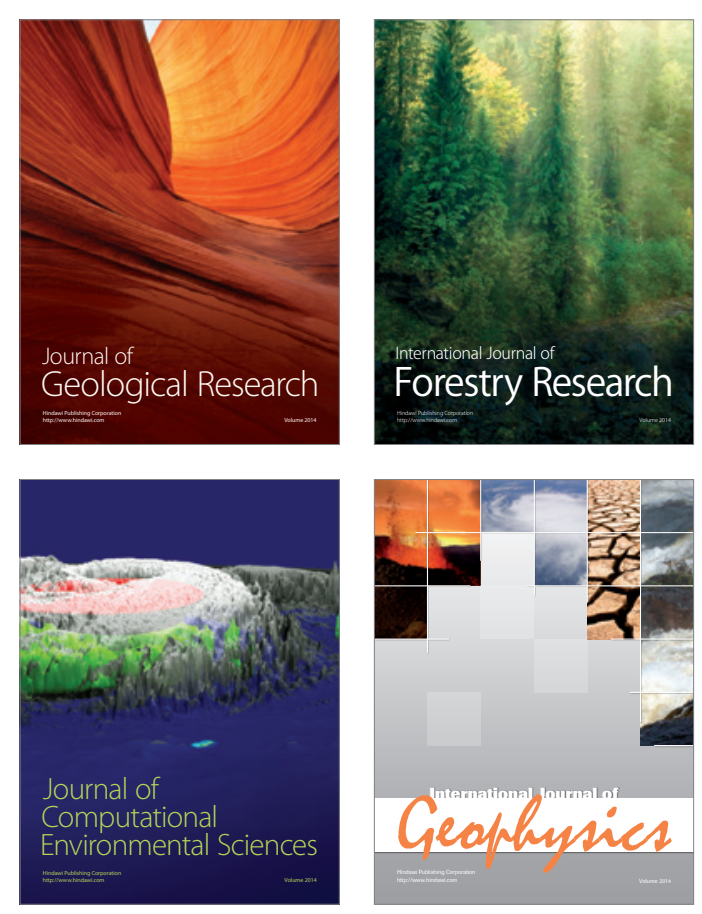
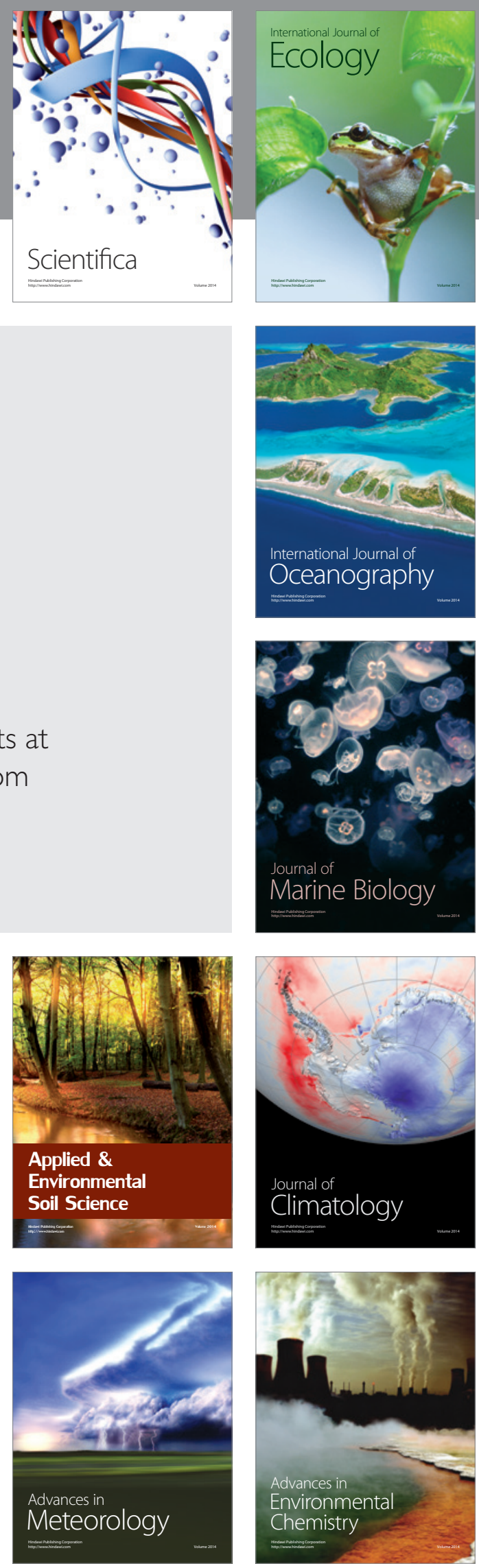